\title{
A social work study on impact of gender, marital status and employment status on internet addiction
}

\author{
Mohammad Reza Iravani $^{\mathrm{a}^{*}}$, Mostafa Rajabi ${ }^{\mathrm{b}}$, Mohammad Golnari Abbasi ${ }^{\mathrm{c}}$ and Hajar Jannesari ${ }^{\mathrm{d}}$
}

\begin{abstract}
${ }^{a}$ Assistant Professor, Department of Social Work, Islamic Azad University Khomeinishahr Branch, Daneshjou Blvd, Iran
${ }^{b}$ Assistant Professor, Department of Economic, Islamic Azad University of Khomeinishahr, Islamic Azad University Khomeinishahr Branch, Daneshjou Blvd, Iran

${ }^{c}$ Department of Economic, Islamic Azad University of Khomeinishahr, Islamic Azad University Khomeinishahr Branch, Daneshjou Blvd, Iran

${ }^{e}$ MS Student, Counseling Department, Islamic Azad University of Khomeinishahr, Khomeinishahr Branch, Daneshjou Blvd, Iran

\section{H R O N I C L E}

Article history:

Received August 14, 2012

Received in revised format

2 January 2013

Accepted 5 January 2013

Available online

January 82013

Keywords:

Internet addiction

Social work study

Cyber space

During the past two decades, internet has penetrated into people's personal lives, significantly. People communicate with each other through internet facilities such as email services, social web pages, etc. Internet has influenced so much of our lives that many people get addicted and it has become a serious issue among different societies. In this study, we perform an empirical study to find the relationship of three issues of age, gender and employment status on internet addiction behavior. The survey selects 190 men and 160 women from a city of NajafAbad located in province of Esfahan, Iran and a questionnaire consists of 35 questions are distributed among them. The survey uses Chi-Square statistics to examine the effects of three mentioned factors and the results indicate that internet addiction is more among singles than married (ChiSquare=19.94). The survey also indicates that internet addition is more on men than women do (Chi-Square=6.64). However, our survey does not find any evidence to believe job employment has any impact on internet addiction.
\end{abstract}

\section{Introduction}

Internet has become one of the most important instruments for internet activities for over two decades (Basu et al., 2011). People prefer to read news through internet activities, purchase goods and services using enterprise web pages and do communicate with their friends and colleagues through social web pages. Some people find it difficult to live without checking their email messages, reading news from internet. Internet facilities are even used in elementary schools for teaching purposes (Tountab Haghighi \& Eskandari, 2012). Mokhtar Makeli et al. (2012) studied internet based educational system, which has recently become popular among university officials. Azad et al.

*Corresponding author. Tel: +989130758065

E-mail addresses: iravani@iaukhsh.ac.ir (M. R. Iravani)

(C) 2013 Growing Science Ltd. All rights reserved. doi: 10.5267/j.msl.2013.01.010 (c) 2013 Growing Science Ltd. All rights reserved. 
(2012) investigated factors influencing the success of travel agencies and found that a good, update and reliable website plays an important role on this business.

Yazdanpanaha and Gazor (2011) explained the relative importance of internet based activities for the success of police operations. Many people try to do some investigation for detecting target customers through people's actions on the internet (Hamzehei et al., 2011; Taghvaa et al., 2011). Ishaq (2011) performed an empirical study on relationship between service quality and customer satisfaction on some Pakistani telecommunication industry. There are also some studies to determine optimal pricing strategies for products sold on the internet (Fathollah Bayati \& Makui, 2011).

Internet has become a reliable source of getting update news and cheap method for get in touch with others. Social network analysis can be useful technique for product development project management (Chen \& Chen, 2011). Business owners find it easier to retain their customers by providing easy access internet facilities (Jomehry et al., 2011). However, any extraordinary use of internet facilities may simply cause some sort of addiction since people may wish to spend most of their valuable times visiting social web pages or reading news. In such circumstances, people's social lives may be jeopardized since they may prefer not to do their regular personal activities, properly. They may stay lonely for long time since they do not participate in social activities.

According to Iravani and Razi (2011) social capital influences social contribution and the internet addiction damages social contribution. Alternatively, married people may see their lives be endanger due to divorce actions taken by their partners. In fact, many officials blame internet addiction as one of the main sources of divorce among people for the past few years. Rafeie rad et al. (2011) performed an empirical investigation on agile supply chain classification for a case study on the Iranian automotive parts supplier and emphasized that having a reliable web based customer relationship management plays an important role for the success of business units. Hawi (2012) studied Internet usage among adolescents, who were the most vulnerable to Internet addiction among the nation.

Douglas et al. (2008) provided an in-depth and comprehensive analysis of internet addiction through a meta-synthesis of qualitative investigations on excessive Internet use over the period 1996-2006. Various constructs pertaining to the domain of Internet addiction were detected and a theoretical model of Internet addiction were studied. Vanea (2011) investigated the relationship between the internet usage, internet usage's purposes, gender and the dimensions of internet addiction. The findings provided an empirical foundation for the adults' counseling practices based on the nowadays people's tendencies to implement intensively/excessively some of types of internet activity.

Ko et al. (2012) recruited papers mentioning coexisting psychiatric disorders of Internet addiction from the PubMed database as at November 3, 2009. They described the updated results for such disorders of Internet addiction, which incorporate substance use disorder, attention-deficit hyperactivity disorder, depression, hostility, and social anxiety disorder. They provided discussion for possible mechanisms accounting for the coexistence of psychiatric disorders and Internet addiction. The review might recommended that combined psychiatric disorders mentioned above could be evaluated and treated to prevent their deteriorating impact on the prognosis of Internet addiction.

On the other hand, Internet addiction ought to be paid more attention to when treating people with these coexisting psychiatric disorders of Internet addiction. They also suggested future necessary research directions, which could provide further information for the understanding of this issue. Aydm and Volkan San (2011) examined the impact of self-esteem on adolescents' Internet addiction. They reported that general self-esteem, social self-esteem, family-home self-esteem and total selfesteem were substantially and negatively associated with Internet addiction. Besides, social selfesteem and family-home self-esteem were determined to be significant predictors of Internet addiction. Chang and Man Law (2008) investigated different factor structure for young's internet addiction test based on a confirmatory study. 
In this study, we perform an empirical study to find the relationship of three issues of age, gender and employment status on internet addiction behavior. The organization of this paper first presents details of the survey in section 2, section 3 explains the results of our study and finally, concluding remarks are given in the last to summarize the contribution of the paper.

\section{The proposed study}

The survey selects 190 men and 160 women from a city of NajafAbad located in province of Esfahan, Iran and a questionnaire consists of 35 questions are distributed among them. They were all between 15 to 45 years old. We have performed our investigation among people who attended Coffee net. The interview took about 25 minutes and all questionnaires were filled within 14 days. All questions were designed in Likert scale and some of the questions were adopted from other similar studies. The survey considers the following three hypotheses,

1. First hypothesis $\begin{cases}H_{0}: & \text { There is no relationship between gender and internet addiction. } \\ H_{1}: & \text { There are some relationship between gender and internet addiction. }\end{cases}$

2. Second hypothesis $\begin{cases}H_{0}: & \text { There is no relationship between marital status and internet addiction. } \\ H_{1}: & \text { There are some relationship between marital status and internet addiction. }\end{cases}$

3. Third hypothesis $\begin{cases}H_{0}: & \text { There is no relationship between employment status and internet addiction. } \\ H_{1}: & \text { There are some relationship between employment status and internet addiction. }\end{cases}$

We used Chi-Square to test three hypotheses of this survey.

\section{The results}

In this section, we present details of our findings based on investigating various hypotheses using the information gathered in this survey.

\subsection{The relationship between gender and internet addiction}

The first hypothesis of this survey is associated with the relationship between gender and addiction to internet. Table 1 demonstrates the results of our survey.

Table 1

The relationship between gender and internet addiction

\begin{tabular}{lccc}
\hline Gender & Addicted to internet & No addiction to internet & Total \\
\hline Female & $120(75 \%)$ & $40(25 \%)$ & $160(100 \%)$ \\
Male & $167(94 \%)$ & $12(6 \%)$ & $190(100 \%)$ \\
\hline Total & 298 & 52 & $350(100 \%)$ \\
\hline
\end{tabular}

As we can observe from the results of Table 1, most people who participated in our survey are addicted to internet. In other words, $94 \%$ of the participants are categorized in this group while only $75 \%$ of the female people who took part in our survey were internet addicted. Chi-Square test is equal to 6.31 with one degree of freedom. Therefore, we can conclude that the null hypothesis is rejected and gender plays an important role on addiction to internet and male people tend to be addicted to internet more than women do. 


\subsection{The relationship between marital status and internet addiction}

The second hypothesis of this survey is associated with the relationship between marital status and addiction to internet. Table 2 shows the results of our survey.

Table 2

The relationship between marital status and internet addiction

\begin{tabular}{lccc}
\hline Marital status & Addicted to internet & No addiction to internet & Total \\
\hline Married & $90(53 \%)$ & $80(47 \%)$ & 170 \\
Single & $160(89 \%)$ & $20(11 \%)$ & 180 \\
\hline Total & 250 & 100 & 100 \\
\hline
\end{tabular}

As we can observe from the results of Table 2, most single people who participated in our survey are addicted to internet. In other words, $71 \%$ of the participants are categorized in this group while only $29 \%$ of them are not addicted to internet. Chi-Square test is equal to 19.94 with one degree of freedom. Therefore, we can conclude that the null hypothesis is rejected and marital status plays an important role on addiction to internet and singles tend to be addicted to internet more than married people do.

\subsection{The relationship between employment status and internet addiction}

The third hypothesis of this survey is associated with the relationship between employment status and addiction to internet. Table 3 shows the results of our survey.

Table 3

The relationship between employment status and internet addiction

\begin{tabular}{lccc}
\hline Marital status & Addicted to internet & No addiction to internet & Total \\
\hline Employed & $201(75 \%)$ & $62(77.5 \%)$ & 263 \\
Unemployed & $69(25 \%)$ & $18(22.5 \%)$ & 87 \\
\hline Total & 270 & 80 & 100 \\
\hline
\end{tabular}

As we can observe from the results of Table 3, most addicted people who participated in our survey are employed. In other words, $75 \%$ of the participants are categorized in this group while only $25 \%$ of them do not have job. Chi-Square test is equal to 1.26 with one degree of freedom. Therefore, we cannot reject the null hypothesis and conclude that the null hypothesis is accepted and employment status does not play an important role on addiction to internet.

\section{Conclusion}

In this paper, we have performed an empirical study to investigate the relationship between various factors including gender, marital and employment status on internet addiction. The study has designed a survey in Likert scale and distributed among some people who used internet in public places called coffee net. The results of our survey have indicated that $94 \%$ of male addicted people who participated in our survey were male while only $75 \%$ of addicted people were female. Therefore, we could conclude that gender played important role on addiction to internet. The other observation of our study indicated that $89 \%$ of the people who were addicted to internet were single and ChiSquare test indicated that single people tend to be addicted to internet more than married people do. However, our investigation did not find any evidence to believe that employment status had any impact on addiction to internet. The results of this study are consistent with many other studies mentioned in this study. 


\section{Acknowledgment}

The authors would like to thank all the participants who cordially participated in our survey and shared their insight with us. We are also grateful to constructive comments received from anonymous referees on earlier version of this work.

\section{References}

Aydm, B., \& Volkan San, S. (2011). Internet addiction among adolescents: The role of self-esteem. Procedia - Social and Behavioral Sciences, 15, 3500-3505.

Azad, N., Seyed Aliakbar, S.M., \& Kordalivand, N. (2011). Investigating effective factors on multimedia advertising: A case study of travel agencies. Management Science Letters, 2(1), 409416.

Basu, R., Upadhyay, P., \& Dan, P.K. (2011). Factors influencing ERP implementation in Indian SMEs: An empirical analysis. Management Science Letters, 1(2), 89-98.

Chang, M.K., Man Law, S.P. (2008). Factor structure for Young's Internet Addiction Test: A confirmatory study. Computers in Human Behavior, 24(6), 2597-2619

Chen, Y.M., \& Chen, M.Y. (2011). Social network analysis aided product development project management: IC Substrates case study. Management Science Letters, 1(2), 107-114.

Douglas, A.C., Mills, J.E., Niang, M., Stepchenkova, S., Byun, S., Ruffini, C., Lee, S.K., Loutfi, J., Lee, J.K., Atallah, M., \& Blanton, M. (2008). Internet addiction: Meta-synthesis of qualitative research for the decade 1996-2006. Computers in Human Behavior, 24(6), 3027-3044

Fathollah Bayati, M., \& Makui, A. (2011). A multi objective geometric programming approach for electronic product pricing problem. Management Science Letters, 1(3), 371-378.

Hamzehei, A., Fathian, M., Farvaresh, H., \& Gholamian, M.R. (2011). A new methodology to study customer electrocardiogram using RFM analysis and clustering. Management Science Letters, $1(2), 139-148$.

Hawi, N. S. (2012). Internet addiction among adolescents in Lebanon. Computers in Human Behavior, 28(3), 1044-1053

Iravani, M.R., \& Razi, Z. (2011). An empirical study to investigate the effects of social capital on social contribution. Management Science Letters, 1(4), 607-612.

Ishaq, M.I. (2011). A study on relationship between service quality and customer satisfaction: An empirical evidence from Pakistan telecommunication industry. Management Science Letters, 1(4), 523-530.

Jomehri, N., Javanshir, H., \& Ebrahim Nezhad, S. (2011). An empirical study to determine the critical success factors on customer retention: A case study of Iranian banking sector. Management Science Letters, 1(2), 223-234.

Ko, C.H., Yen, J.Y., Yen, C.F., Chen, C.S., \& Chen, C.C. (2012). The association between Internet addiction and psychiatric disorder: A review of the literature. European Psychiatry, 27(1), 1-8

Mokhtar Makeli, P., Babakhani, M., \& Bodaghi, M. (2012). Determination and evaluation of the parameters influencing the virtual educational costs. Management Science Letters, 2(1), 131-136.

Rafeie rad, D., Amiri, M., Gardeshi, M. \& Siahkali Moradi, J. (2011). Application of factor analysis for agile supply chain classification: A case study on the Iranian automotive parts supplier (SAPKO). Management Science Letters, 1(4), 457-466.

Taghvaa, M.R., Hosseini Bamakan, S.M., \& Toufanic, S. (2011). A data mining method for service marketing: A case study of banking industry. Management Science Letters, 1(3), 253-262.

Tountab Haghighi, S. \& Eskandari, M. (2012). A study on barriers of using information technology on learning and teaching in elementary schools. Management Science Letters, 2(1), 417-424. 
Vanea, M.O. (2011). Intensive / excessive use of internet and risks of internet addiction among specialized workers - gender and online activities differences. Procedia - Social and Behavioral Sciences, 30, 757-764.

Yazdanpanaha, A.A., \& Gazor, H. (2012). Detecting success factors of electronic customer relationship management (e_CRM) system to establish an appropriate model in police call centre of Iran. Management Science Letters, 2(1), 339-350. 